University of Nebraska - Lincoln

DigitalCommons@University of Nebraska - Lincoln

\title{
Ontogenetic shift in buoyancy and habitat in the Antarctic toothfish, Dissostichus mawsoni (Perciformes: Nototheniidae)
}

Thomas J. Near

University of California, tjnear@ucdavis.edu

Sabrina E. Russo

University of Nebraska - Lincoln, srusso2@unl.edu

Christopher D. Jones

Southwest Fisheries Science Center

Arthur L. DeVries

University of Illinois at Urbana-Champaign

Follow this and additional works at: https://digitalcommons.unl.edu/bioscifacpub

Near, Thomas J.; Russo, Sabrina E.; Jones, Christopher D.; and DeVries, Arthur L., "Ontogenetic shift in buoyancy and habitat in the Antarctic toothfish, Dissostichus mawsoni (Perciformes: Nototheniidae)" (2003). Faculty Publications in the Biological Sciences. 254.

https://digitalcommons.unl.edu/bioscifacpub/254

This Article is brought to you for free and open access by the Papers in the Biological Sciences at DigitalCommons@University of Nebraska - Lincoln. It has been accepted for inclusion in Faculty Publications in the Biological Sciences by an authorized administrator of DigitalCommons@University of Nebraska - Lincoln. 


\section{Ontogenetic shift in buoyancy and habitat in the Antarctic toothfish, Dissostichus mawsoni (Perciformes: Nototheniidae)}

\begin{abstract}
Buoyancy measurements and depth of capture were taken on 70 individuals of Dissostichus mawsoni collected from the Southern Scotia Arc and McMurdo Sound, Antarctica, to examine the effect of age on buoyancy and habitat use. Standard lengths (SL) ranged from 10.4 to $138.0 \mathrm{~cm}$. Juveniles were not buoyant (heavy in water), whereas adults were neutrally buoyant. The slope of the relationship between buoyancy and SL was significantly negative for juveniles (individuals less than $81 \mathrm{~cm} \mathrm{SL}$ ), but there was no significant relationship for adults (individuals greater than $81 \mathrm{~cm} \mathrm{SL}$ ). These results demonstrate an ontogenetic shift in buoyancy. For juveniles, depth of capture and SL had a significantly positive relationship. As individuals reach adulthood they achieve neutral buoyancy and appear to use deeper water habitats. This interpretation is supported by a significant positive correlation between buoyancy and depth of capture for juveniles. Changes in buoyancy with maturation of juveniles may also be associated with a shift in habitat use. Juveniles appear to exploit benthic habitats, whereas adults use the entire water column over deeper water. Given the differences in
\end{abstract}

\section{T.J. Near $(\varangle)$}

Center for Population Biology, University of California,

One Shields Ave., Davis, CA 95616, USA

E-mail: tjnear@ucdavis.edu

Tel.: + 1-530-7521112

Fax: + 1-530-7521449

S.E. Russo

Program in Ecology and Evolutionary Biology,

University of Illinois, 515 Morrill Hall,

Urbana, IL 61801, USA

C.D. Jones

US Antarctic Marine Living Resources Program, Southwest Fisheries Science Center, P.O. Box 271, La Jolla, CA 92038, USA

\section{A.L. DeVries}

Department of Animal Biology, University of Illinois, 515 Morrill Hall, Urbana, IL 61801, USA prey species available in these habitats and based on our results, we predict that diets of juveniles and adults should differ significantly. We also hypothesize that accumulation of lipid deposits from the diet during maturation of juveniles may account for the ontogenetic shift in buoyancy and allow neutral buoyancy to be achieved in adulthood.

\section{Introduction}

The monophyletic Notothenioidei dominates the fish fauna of the Southern Ocean surrounding Antarctica. Morphological and ecological diversification in this lineage, which is comprised of approximately 120 species, is substantial and thought to be associated with exploitation of novel niches in the water column (Eastman 1993). Most notothenioids are benthic and heavier than seawater, and all species lack a swimbladder (Eastman and DeVries 1982). However, previous investigators have noted a trend within a few notothenioid lineages towards pelagism, allowing exploitation of underutilized and food-rich midwater habitats around the Antarctic continent (Eastman 1993; Klingenberg and Ekau 1996). Two notothenioid species, Dissostichus mawsoni and Pleuragramma antarcticum have been found to be neutrally buoyant in seawater as adults (Eastman and DeVries 1982). Aethotaxis mitopteryx is thought to exhibit neutral buoyancy, but the buoyancy of non-preserved specimens has never been measured (Eastman and DeVries 1982; Eastman 1993). Despite using similar water column habitats, the ecology of these three species differs considerably. $P$. antarcticum and A. mitopteryx are intermediate-sized (maximum $25 \mathrm{~cm}$ and $42 \mathrm{~cm}$ total length, respectively), laterally compressed, silver-colored, planktotrophic species, whereas $D$. mawsoni is the largest notothenioid species (maximum total length $175 \mathrm{~cm}$ ), and is a piscivore that feeds heavily on P. antarcticum (Daniels 1981; Eastman 1985b; DeWitt et al. 1990). 
The evolution of neutral buoyancy observed in notothenioids has been hypothesized to have at least two origins in the history of the diversification of the clade (Eastman 1993). However, recent phylogenetic analysis of morphological variation in notothenioids recovered a monophyletic clade, Pleuragrammatinae, containing all of the neutrally buoyant notothenioids, $P$. antarcticum, A. mitopteryx, and D. mawsoni (Balushkin 2000). This result is not in conflict with previous mitochondrial DNA analyses of notothenioid phylogeny, as these studies failed to resolve the phylogenetic relationships of these species (Bargelloni et al. 2000).

Buoyancy in notothenioids is achieved through reduction of skeletal ossification and the presence of subcutaneous and intramuscular lipid deposits (DeVries and Eastman 1978; Eastman and DeVries 1981, 1982). Neutrally buoyant notothenioid species have significantly greater amounts of total lipids in their bodies than do non-buoyant species (Clarke et al. 1984; Friedrich and Hagen 1994), and the accumulation of lipids is hypothesized to provide lift for neutral buoyancy in the absence of a swimbladder. Associated with the increased amounts of lipids in neutrally buoyant notothenioid species is a reduction in ossification of the skeleton (DeVries and Eastman 1978; Eastman and DeVries 1981; Eastman 1985a). The weight of ashed skeletons of D. mawsoni, P. antarcticum, and A. mitopteryx are proportionately the lightest among examined notothenioids, indicating that the skeletons of these species exhibit a low mineral content, which contributes to the reduced density of these species in seawater (Eastman and DeVries 1982).

Among the neutrally buoyant notothenioid species, $P$. antarcticum exhibits the most specialized modifications for lipid deposition. Lipid stores in P. antarcticum are in subcutaneous and intramuscular sacs composed of modified adipocytes surrounding large lipid droplets, a condition unique among vertebrates (DeVries and Eastman 1978; Eastman 1988; Eastman and DeVries 1989). A. mitopteryx contains subcutaneous and intramuscular lipid deposits but, unlike $P$. antarcticum, its lipids are contained in adipose tissue typical of most vertebrates (Eastman and DeVries 1982). Lipids in $D$. mawsoni are contained in subcutaneous and muscular deposits of adipose tissue (Eastman and DeVries 1981; Eastman 1988). Unlike $P$. antarcticum and A. mitopteryx, D. mawsoni does not have any intramuscular lipid deposits.

A thorough analysis of total lipid content in five notothenioid species discovered an ontogenetic increase of lipid accumulation in $P$. antarcticum. Juvenile specimens exhibited proportionately lower amounts of lipid than adult specimens, a trend supported by a significant correlation between lipid content and standard length (Friedrich and Hagen 1994). Unfortunately, buoyancy measurements are not available for these specimens to investigate either the relationship between proportional lipid content and buoyancy or the possibility of an ontogenetic shift in buoyancy.
Previously published information on buoyancy and lipid content of D. mawsoni is restricted to adults collected at McMurdo Sound, Ross Island (Eastman and DeVries 1982; Clarke et al. 1984). Furthermore, little is known regarding the diet and habitat use of juvenile $D$. mawsoni. In this study we measure the buoyancy of different sizes of $D$. mawsoni to determine if there is an ontogenetic shift in buoyancy of this species and the relationship of buoyancy to depth of capture. These results are discussed in relation to the ecology of juvenile D. mawsoni and the functional biology of neutral buoyancy in notothenioid fishes.

\section{Materials and methods}

Specimens were collected at locations in the southern Scotia Arc in March 2001, and in McMurdo Sound, Ross Island in December 2001. The southern Scotia Arc specimens were collected in conjunction with a demersal finfish trawl survey of the South Shetland Islands aboard the R.V. Yuzhmorgeologiya conducted by the US AMLR (Antarctic Marine Living Resources) Program (Jones et al. 2001) for the management of finfish resources by CCAMLR (Commission for the Conservation of Antarctic Marine Living Resources) in this area. The fishing gear was a commercial size bottom trawl with vented V-doors, an average mouth width $18.2 \mathrm{~m}$ $(15.5-21.0 \mathrm{~m})$, and height of $8.5 \mathrm{~m}(6.2-10.7 \mathrm{~m})$. The survey was based on a random depth stratified sampling design consisting of 71 stations between 50 and $500 \mathrm{~m}$; each trawl haul lasted approximately $30 \mathrm{~min}$. D. mawsoni were captured at 32 of these stations in depths ranging from 89 to $409 \mathrm{~m}$.

Specimens from McMurdo Sound were collected approximately $8 \mathrm{~km}$ from the US McMurdo Station $\left(77^{\circ} 51^{\prime} \mathrm{S}, 166^{\circ} 40^{\prime} \mathrm{E}\right)$ located on Ross Island. Fishes were collected using a vertical set line of $2.4 \mathrm{~mm}$ stainless steel cable with baited hooks, housed in a fishing hut located over a $107 \mathrm{~cm}$ hole through the sea ice, which was approximately $2-3 \mathrm{~m}$ thick. Preliminary efforts at catching $D$. mawsoni over shallow water in McMurdo Sound have yielded few specimens while large numbers of specimens are captured near the bottom in $400-500 \mathrm{~m}$ of water (A.L. DeVries, personal observation).

Fishes were anesthetized using MS-222 and standard length (SL) was measured to the nearest $0.1 \mathrm{~cm}$. Juvenile fishes were identified as measuring less than $81 \mathrm{~cm}$ SL, based on previous assessments of gonad maturity (Yukhov 1971; Eastman and DeVries 2000). Buoyancy was measured using the protocol developed by Eastman and DeVries (1982) and is summarized here. The weight in air of anesthetized fishes was determined using a top-loading electronic balance for small specimens, and large specimens were weighed using a dial-reading platform scale with a 91-kg capacity. The weight in water was measured by attaching the lower jaw to a bent insect pin or small-gauge needle connected to a piece of silk suture. The other end of the silk thread was attached to an Ohaus triple beam balance or an electronic balance resting on a stable platform suspended over the water container. After removing air from the gill and oral cavities, weight in water was determined by suspending the specimen, attached to the scale with the thread, into a large container of seawater maintained at the temperature at which the fishes were collected $\left(1.0-2.0^{\circ} \mathrm{C}\right.$ for Scotia Arc, $-1.9^{\circ} \mathrm{C}$ for McMurdo Sound). Buoyancy (B), the percentage of weight in air supported when in water, was estimated from the ratio of weight in water over weight in air $\times 100$. Neutrally buoyant individuals were identified as those where $\mathrm{B}<0.06 \%$ (Eastman 1993).

Inspection of the scatter plots of buoyancy versus SL, and depth of water at collection location versus SL revealed that the relationships between these parameters differ between juveniles and adults (Fig. 1). We used the general linear model procedure in SAS (The SAS System Release 8.1) to conduct an analysis of covariance 

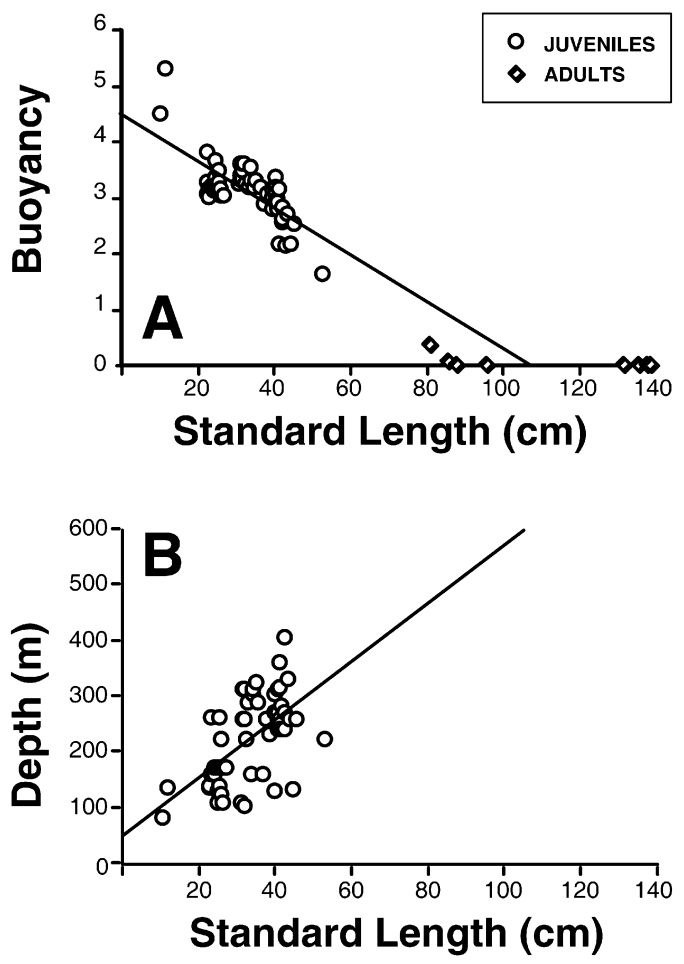

Fig. 1 Scatterplots of A buoyancy and B depth of capture versus standard length in Dissostichus mawsoni. Note that regression lines are fit through data for juveniles only

for the relationship between buoyancy and SL (covariate). We included a categorical independent variable (age, represented as juvenile or adult) to test for potential differences in the slope of the relationship ( $\mathrm{SL} \times$ age interaction term) between juveniles and adults. We used Pearson correlation to test for a relationship between depth and SL and between buoyancy and depth in juveniles.

\section{Results}

We obtained measurements of standard length (SL), buoyancy, and depth for $70 \mathrm{D}$. mawsoni individuals. Of these, eight were adults (SL: $81.0-138.0 \mathrm{~cm}$ ) captured at McMurdo Sound, and the remaining individuals were juveniles (SL: 10.4-53.1 cm) from the Southern Scotia Arc. The relationship of buoyancy to SL was significantly different for adults and juveniles (significant interaction term SL $\times$ age; Table 1; Fig. 1a). Buoyancy increased significantly with $\mathrm{SL}$ for juveniles $(\mathrm{b}=$ $\left.-0.039, \mathrm{SE}_{\mathrm{b}} 0.007, \mathrm{df}=66, t=-5.38, P<0.0001\right)$, but

Table 1 Analysis of covariance for the relationship of buoyancy with standard length $(S L)$. The coefficient of determination for the fullmodel was $r^{2}=0.91$

\begin{tabular}{lll}
\hline $\begin{array}{l}\text { Source } \\
\text { Buoyancy }\end{array}$ & $F$-value $(1,66)$ & Probability \\
\hline SL & 39.92 & $<0.0001$ \\
Age & 50.32 & $<0.0001$ \\
SL $\times$ age & 31.18 & $<0.0001$ \\
\hline
\end{tabular}

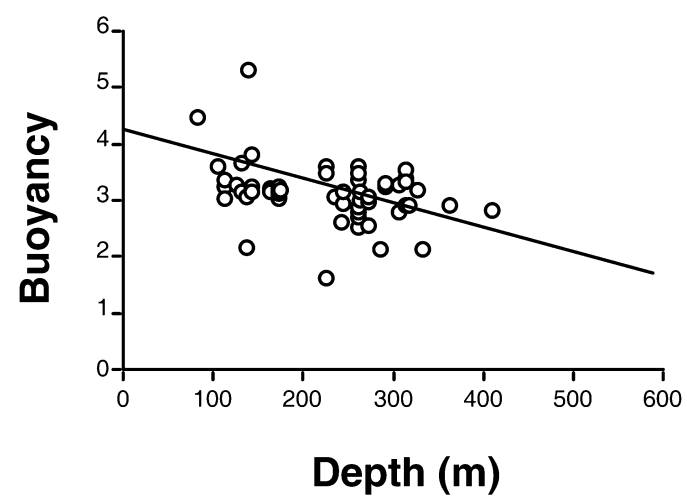

Fig. 2 Correlation of buoyancy with depth of capture in juvenile D. mawsoni

had no significant relationship with SL for adults $(P$ $=0.6009$ ). This result was paralleled in the relationship between depth and SL. As juveniles increased in size, they were captured in deeper water $(r=0.61, n=62, P$ $<0.0001$ ), whereas adults tended to be captured in the deepest depths of water sampled. Juvenile buoyancy had a significant negative correlation with depth $(r=-0.346$, $P=0.0059$ ), suggesting that juvenile $D$. mawsoni occupying deeper water habitats tended to be more buoyant (Fig. 2).

\section{Discussion}

A pattern of repeated evolution of pelagic species into the under-exploited water column habitats of the Southern Ocean has been proposed as a model for the adaptive radiation of notothenioid fishes (Eastman 1993; Klingenberg and Ekau 1996; Eastman and McCune 2000). Our analyses of buoyancy variation within $D$. mawsoni indicate that the species exhibits a strong ontogenetic shift in buoyancy (Fig. 1A, Table 1). Compared with larger-sized adults, juveniles are less buoyant (greater weight in water) and gradually become more buoyant with increasing size until they reach a SL of $81 \mathrm{~cm}$ (the adult size class), at which time they are neutrally buoyant. A similar ontogenetic shift in depth is seen (Fig. 1B). It appears that juveniles are found in shallower habitats and adults are not, and that adults and juveniles are not captured in the same depth of water, although this apparent relationship could be affected by the fishing method used. A similar pattern of size segregation by depth is observed in the neutrally buoyant $P$. antarcticum, in which the smallest individuals are found in the shallowest depths, and adults occupy the deepest waters (Hubold 1984; Kellerman 1986).

Attaining neutral buoyancy would potentially allow D. mawsoni to exploit food sources in the entire water column while reducing energy expenditures in overcoming the effects of gravity. Previously, large adult D. mawsoni have been captured primarily in deep water 
near the bottom, and not in the water column. However, video cameras mounted on Weddell seals (Leptonychotes weddellii) over water approximately $540 \mathrm{~m}$ deep in McMurdo Sound have encountered large D. mawsoni in the water column at a mean depth of $132 \mathrm{~m}$ below the surface (Fuiman et al. 2002). The occurrence of $D$. mawsoni near the bottom, as well as in the water column, is possibly a result of exploiting benthic prey at times of the year when prey is scarce in the pelagic habitat. Our findings indicate that as juveniles become more buoyant, they occupy deeper water habitats (Fig. 2). We hypothesize that the ontogenetic shift towards use of deeper waters offers more water column habitat to exploit, while deeper portions of the depth range may provide a refuge from predation by seals.

If the ontogenetic shift in depth allows juvenile and adult $D$. mawsoni access to different food resources, then a similar ontogenetic shift in diet would be expected. Previous observations of diet and depth of water at capture in D. mawsoni have noted differences between juvenile and adults that parallel our findings. Adult $D$. mawsoni are found in deep water habitats, often far from coastal regions (Yukhov 1971; Ekau 1990; Eastman and DeVries 2000; Vacchi et al. 2000). The diet of adults suggests that they feed in water column, rather than benthic, habitats because the majority of prey consists of squid, pelagic and cryopelagic fishes, and mysid shrimp (Yukhov 1971; Eastman 1985a, 1985b; Pakhomov and Tseytlin 1992). In contrast, the smallest juvenile D. mawsoni encountered (11-71 cm SL) have been reported from shallow, near-shore habitats (Yukhov 1971; Pakhomov and Pankratov 1992; Eastman and DeVries 2000). Direct observation by underwater video suggests that juvenile D. mawsoni use benthic habitats (Eastman and Barry 2002). Although the diet of juvenile D. mawsoni is poorly known, stomachs of juveniles ranging in size from 10.4 to $11.8 \mathrm{~cm}$ SL contained mainly euphausiids and benthic larval fishes (Pakhomov and Pankratov 1992). Stomachs of juveniles in this study contained primarily euphausiids, mysids, and benthic juvenile fishes, and the size and frequency of prey fishes in the diet increased with SL (Jones et al. 2001; T.J. Near, personal observation).

The association between lipid deposits and buoyancy in neutrally buoyant notothenioids provides a potential mechanism to explain the ontogenetic trend in buoyancy observed in $D$. mawsoni. We hypothesize that the observed ontogenetic accumulation of lipids in $P$. antarcticum (Friedrich and Hagen 1994) also occurs in $D$. mawsoni. Triacylglycerols are the major lipid class in all notothenioid species examined (Clarke et al. 1984; Hagen et al. 2000), with an abundance of long-chain unsaturated fatty acids in neutrally buoyant $P$. antarcticum and A. mitopteryx (Hagen et al. 2000). These particular fatty acids are common components of two abundant Antarctic copepod species, Calanoides acutus and Calanus propinquus (Hagen et al. 2000). These copepods are likely to be important components of the diet for $P$. antarcticum and A. mitopteryx. We hypothesize that, as juveniles, $D$. mawsoni feed on prey items that facilitate accumulation of subcutaneous lipid deposits that increase buoyancy, resulting in neutral buoyancy being achieved at adulthood. Additional data are required to evaluate this hypothesis further. First, diets of all size classes of $D$. mawsoni must be better described to quantify differences between juveniles and adults. Second, the lipid content and composition of important prey species should be quantified and compared with those of $D$. mawsoni juveniles and adults. Finally, an ontogenetic shift in lipid content of muscle and subcutaneous tissue that parallels that of buoyancy must be demonstrated.

In summary, this study has documented a significant ontogenetic shift in both buoyancy and depth in $D$. mawsoni (Fig. 1). This finding is significant in that it parallels ecological variation in habitat use and diets of juvenile and adults in this species. Our findings are consistent with previous studies and indicate that juvenile D. mawsoni use benthic habitats in shallower water, whereas adults use pelagic habitats in deeper water. As juveniles grow they become more buoyant, accompanied by a gradual shift towards use of deeper water habitats (Fig. 2). We propose that the mechanism of change in buoyancy is an ontogenetic increase in lipid deposits accumulated from a lipid-rich diet as juveniles. This hypothesis can be tested through lipid content analysis, histological studies of subcutaneous lipid deposits, and a better understanding of diet in D. mawsoni. Phylogenetic analyses indicate a single evolutionary origin of lipid deposit-facilitated neutral buoyancy in notothenioids. Adaptive diversification associated with water column habitat use is reflected in the substantial variation in ecology and morphology among the monophyletic, neutrally buoyant notothenioids.

Acknowledgements We would like to thank the officers and crew of the R.V. Yuzhmorgeologiya. Support for collecting in the South Shetlands was provided by the United States Antarctic Marine Living Resources (AMLR) Program. The United States National Science Foundation, OPP 99-09841 to A.L. DeVries funded efforts at McMurdo Sound. Support and facilities for T.J. Near were provided by the Center for Population Biology Postdoctoral Fellowship at the University of California, Davis. Helpful comments on the manuscript were provided by Peter C. Wainwright and C. Darrin Hulsey.

\section{References}

Balushkin AV (2000) Morphology, classification, and evolution of notothenioid fishes of the Southern Ocean (Notothenioidei, Perciformes). J Ichthyol 40:S74-S109

Bargelloni L, Marcato S, Zane L, Patarnello T (2000) Mitochondrial phylogeny of notothenioids: a molecular approach to Antarctic fish evolution and biogeography. Syst Biol 49:114-129

Clarke A, Doherty N, DeVries AL, Eastman JT (1984) Lipid content and composition of three species of Antarctic fish in relation to buoyancy. Polar Biol 3:77-83

Daniels RA (1981) Feeding ecology of some fishes of the Antarctic Peninsula. Fish Bull 80:575-588

DeVries AL, Eastman JT (1978) Lipid sacs as a buoyancy adaptation in an Antarctic fish. Nature 271:352-353 
DeWitt HH, Heemstra PC, Gon O (1990) Nototheniidae. In: Gon O, Heemstra PC (eds) Fishes of the Southern Ocean. J.L.B. Smith Institute of Ichthyology, Grahamstown, South Africa, pp 279-331

Eastman JT (1985a) The evolution of neutrally buoyant notothenioid fishes: their specializations and potential interactions in the Antarctic marine food web. In: Siegfried WR, Condy PR, Laws RM (eds) Antarctic nutrient cycles and food webs. Springer, Berlin Heidelberg New York, pp 430-436

Eastman JT (1985b) Pleuragramma antarcticum (Pisces, Nototheniidae) as food items for other fishes in McMurdo Sound, Antarctica. Polar Biol 4:155-160

Eastman JT (1988) Lipid storage systems and the biology of two neutrally buoyant Antarctic notothenioid fishes. Comp Biochem Physiol B 90:529-537

Eastman JT (1993) Antarctic fish biology: evolution in a unique environment. Academic Press, San Diego

Eastman JT, Barry JP (2002) Underwater video observation of the Antarctic toothfish Dissostichus mawsoni (Perciformes: Notothenioidei) in the Ross Sea, Antarctica. Polar Biol 25:391395

Eastman JT, DeVries AL (1981) Buoyancy adaptations in a swimbladderless Antarctic fish. J Morphol 167:91-102

Eastman JT, DeVries AL (1982) Buoyancy studies of notothenioid fishes in McMurdo Sound, Antarctica. Copeia 1982:385-393

Eastman JT, DeVries AL (1989) Ultrastructure of the lipid sac wall in the Antarctic notothenioid fish Pleuragramma antarcticum. Polar Biol 9:333-335

Eastman JT, DeVries AL (2000) Aspects of body size and gonadal histology in the Antarctic toothfish, Dissostichus mawsoni, from McMurdo Sound, Antarctica. Polar Biol 23:189-195

Eastman JT, McCune AR (2000) Fishes on the Antarctic continental shelf: evolution of a marine species flock? J Fish Biol 57:84-102

Ekau W (1990) Demersal fish fauna of the Weddell Sea, Antarctica. Antarct Sci 2:129-137
Friedrich C, Hagen W (1994) Lipid contents of five species of notothenioid fish from high-Antarctic waters and ecological implications. Polar Biol 14:359-369

Fuiman LA, Davis RW, Williams TM (2002) Behavior of midwater fishes under the Antarctic ice: observations by a predator. Mar Biol 140:815-822

Hagen W, Kattner G, Friedrich C (2000) The lipid compositions of high-Antarctic notothenioid fish species with different life strategies. Polar Biol 23:785-791

Hubold G (1984) Spatial distribution of Pleuragramma antarcticum (Pisces: Nototheniidae) near the Filchner- and Larsen ice shelves (Weddell Sea, Antarctica). Polar Biol 3:231-236

Jones CD, Kock K-H, Wilhelms S, Ramm D, Ashford J, Near T, Emery J, Gong N, Flores H, Banks A, Prowse M (2001) AMLR 2000/2001 field season report. US Antarctic Marine Living Resources Program (AMLR), La Jolla, Calif.

Kellermann A (1986) Geographical distribution and abundance of postlarval and juvenile Pleuragramma antarcticum (Pisces, Notothenioidei) off the Antarctic Peninsula. Polar Biol 6:111120

Klingenberg CP, Ekau W (1996) A combined morphometric and phylogenetic analysis of an ecomorphological trend: pelagization in Antarctic fishes (Perciformes: Nototheniidae). Biol J Linn Soc 59:143-177

Pakhomov YA, Pankratov SA (1992) Feeding of juvenile notothenioid fishes of the Indian Ocean sector of the Antarctic. J Ichthyol 32:28-37

Pakhomov YA, Tseytlin VB (1992) Diet of seven species of Antarctic fishes and estimation of their daily rations. J Ichthyol 32:31-41

Vacchi M, Mesa ML, Greco S (2000) The coastal fish fauna of Terra Nova Bay, Ross Sea, Antarctica. In: Faranda FM, Guglielmo L, Ianora A (eds) Ross Sea ecology. Springer, Berlin Heidelberg New York, pp 457-468

Yukhov VL (1971) The range of Dissostichus mawsoni Norman and some features of its biology. J Ichthyol 11:8-18 